Scientific Review - Engineering and Environmental Sciences (2020), 29 (3), 388-396

Sci. Rev. Eng. Env. Sci. (2020), 29 (3)

Przegląd Naukowy - Inżynieria i Kształtowanie Środowiska (2020), 29 (3), 388-396

Prz. Nauk. Inż. Kszt. Środ. (2020), 29 (3)

http://iks.pn.sggw.pl

DOI 10.22630/PNIKS.2020.29.3.33

Roman TRACH ${ }^{1}$, Sergey BUSHUYEV ${ }^{2}$

${ }^{1}$ Warsaw University of Life Sciences - SGGW, Institute of Civil Engineering

${ }^{2}$ Kyiv National University of Construction and Architecture

\title{
Analysis communication network of construction project participants
}

Key words: social network analysis, centrality measures of nodes, construction project, communication, knowledge

\section{Introduction}

Construction projects delivery was characterized by Ochieng and Price (2009), as a complex process taking place in a turbulent environment with unpredictable work patterns, especial work and temporarily organized teams. In addition, the construction industry is characterized by limited resources and a high level of competition. Limited resources and a competitive environment determine knowledge and information as a particularly important resource for the development of the construction industry.

After the concept of knowledge management was first applied in construction projects, scientists began a discussion on how to manage knowledge and information in specific projects, taking into account the problems associated with the specifics of the construction industry. A significant part of the work was aimed at the analysis of knowledge management in one organization, in which knowledge is considered as a valuable resource or intellectual asset (Pryke, 2005; Ochieng \& Price, 2009; Trach, Pawluk \& Lendo-Siwicka, 2020). A study of knowledge management between project participants will provide researchers with an improved understanding of the processes and will further improve the construction projects efficiency. Recently, the integration of the general knowledge of participants in a construction project has been gaining importance.

The integration of knowledge is a process in which people who have previously gained experience in specialized fields of knowledge share it in order to achieve a common result. The knowledge integration brings together project participants and can mitigate the short- 
comings that arise due to the fragmentation of the construction project stages. The knowledge integration between organizations involved in the construction project delivery has already attracted researcher's attention. Baiden, Price and Dainty (2006) supposed that a joint project team can be very effective, as team members from different organizations create a pool of different skills and knowledge. Nicolini, Holti and Smalley (2001) indicated that when managing a construction project, not only material resources and information should be integrated, but also the knowledge and participants experience. Briscoe and Dainty (2005) also studied topical issues construction project integration and came to the conclusion that the knowledge in the project is as important as the issues of communication and information exchange.

A communication network is one of the elements of a knowledge management system in projects and serves to organize and maintain information links between project participants. Pryke (2012) defined the construction project as a network of organizations connected by information flows and relationship communication networks. Successful project management very often depends on the effectiveness of relationships between project team members (PMI, 2001; Trach \& Lendo-Siwicka, 2018). The communication of project teams includes individuals, information flows (knowledge, information), tools for processing information flows and barriers that arise in the way of information.

Scientists often use social network analysis (SNA) to identify key elements in social, biological, physical, commu- nication, transport and other networks (Marsden \& Lin, 1982). Recently, network analysis has been used in studies directly related to construction, in particular for the analysis of projects structure. One of the first articles was devoted to communication problems between the project main participants: client, project manager, architect and contractor (Loosemore, 1998). Madani, Daim and Weng (2017) used network analysis to study intelligent buildings, to find the most effective technologies and new innovative opportunities. Abbsaian-Hosseini, Liu and Hsiang (2017) analysed the relationship between the degree centrality and effectiveness in the implementation of joint work by construction teams. Chinowsky and Songer (2011) diagnosed the networks that arise in construction projects, and noticed that there are social and informational connections between the project participants. They argue that successful teams demonstrate a high level of communication between team members and a high cooperation degree. Pryke, Badi, Almadhoob, Soundararaj and Addyman (2018) analysed the self-organizing networks that emerged from the infrastructure project delivery. The data obtained show that these networks exhibit a high degree of sparseness, short paths and high clustering in dense communities around participants with many links. Among recent studies, two articles should be pointed out in which the authors analyse the relationship among participants in self-organizing networks of construction project. Using SNA allowed them to understand and identify some problems and shortcomings of projects (Śladowski, Radziszewska-Zielina \& Kania, 2019). 
Later, they discovered an anomaly in communication between the participants and proposed an optimization method to increase the effectiveness of using network communication (Radziszewska-Zielina, Śladowski, Kania, Sroka \& Szewczyk, 2019).

Social network analysis tools allow you to explore various indicators of networks that can be classified depending on the direction of analysis:

1. Indicators for analysing the network (graph) characteristics: density, average degree of the network, average path length, clustering coefficient, which shows how fully all project teams participants are involved in the communication structure.

2. Indicators for the analysis of network participants (nodes and edges): centrality measures, indicating the discontinuity degree of the project participants and the relationships between them.

3. Indicators for the analysis of communities in the network, which indicate the degree to which the nodes in the graph tend to group into communities (clusters).

The purpose of this work is the calculation and analysis centrality measures for participants in the construction project delivery. Centrality measures can answer the following questions:

- whether the node is influential or central to the network,

- whether the node is critical for the flow of information in the network.

\section{Material and methods}

Social network analysis has based on methods and tools of graph theory. Mathematically, the links network in the project can be represented in the form of an undirected graph $G=(V, E)$, where $V$ is non-empty set of nodes, and $E$ is the set of pairs of the form $e=(u, v), u$, $v \in V$, which are called edges, and the nodes $u$ and $v$ are the ends of the edges. If we consider the project as a graph, then its participants will be represented by nodes of the graph, and the connections between them are the edges of the graph.

In this study, a graph is undirected weighted type of graph whose nodes (network participants) are connected by edges. The link strength between network participants is displayed using the measure "weight of edge". The edge sets in this case consists of unordered pairs of nodes $(u, v)=$ $=(v, u)$ (Bornholdt \& Schuster, 2003).

To investigate the communication network between the project participants, centrality measures of nodes were analysed: degree centrality, betweenness centrality, eigenvector centrality and measure of importance PageRank. For an undirected graph, degree centrality of nodes can be written as the adjacency matrix (Freeman, 1978). The adjacency matrix of the graph $G=(V, E)$ with the number of nodes $n$ is a square matrix $A$ of size $n$ in which the value of $a_{i j}$ is equal to the number of edges from node $i$ to node $j$. Thus, degree centrality of node $i$ can be calculated by the formula:

$C d(i)=\frac{\sum_{j=1}^{n} a_{i j}}{n-1}$

The logical continuation in the evolution of degree centrality is eigenvector centrality. The significant difference between these two metrics is that when 
calculating of degree centrality, only the number of neighbouring nodes is used, without taking the level of their influence in network. Obviously, not all neighbour nodes are equal. In many cases, the importance of a node increases due to the presence of links with nodes that have a high level of influence in network. This means that nodes with a few very important neighbours in their influence can surpass nodes with many links connecting them to unimportant nodes.

Eigenvector centrality of node $i$ is proportional to the sum of the centrality neighbouring nodes $i$ can be calculated by the formula (Bonacich, 1987)

$$
C e(i)=k_{1}^{-1} \sum_{j} a_{i j} x_{j}
$$

where:

$k_{j}$ - eigenvalues of adjacency matrix $A$, $k_{i}$ - the largest of them,

$a_{i j}$ - adjacency matrix element,

$x_{j}$ - eigenvector centrality of node $j$.

The measure eigenvector centrality of node $i$, which was obtained due to the high level of prestige of node $j$, can distort the real influence of node $i$ in network.

This problem was taken into account when calculating the measure of centrality PageRank (Page, Brin, Motwani \& Winograd, 1999). The measure of node PageRank is calculated using the formula

$\operatorname{Cpr}_{(i)}=\alpha \sum_{j} a_{i j} \frac{x_{j}}{k_{j}^{\text {out }}}+\beta$

where:

$\alpha, \beta$ - constants,

$a_{i j}$ - adjacency matrix element,

$x_{j}$ - eigenvector centrality of node $j$, $k_{j}^{\text {out }}$ - number of edges out coming from node $j$.

If the node $j$ does not have out coming edges, then $k_{j}^{\text {out }}$ is equated to one in order to avoid division by zero.

Measure betweeness centrality shows how paths connecting other participants pass through a network member. In other words, this measure indicates how much this participant acts as a broker for connections between other network participants. A network participant can influence its other participants, supporting, delaying or disrupting the process of transmitting knowledge and information. In any case, it has the potential to carry out such actions.

Measure betweeness centrality is calculated as the ratio of the shortest paths running through a given node to the total number of all shortest (Freeman, 1977)

$C b(i)=\sum \frac{g_{k j}(i)}{g_{k j}}$

where:

$g_{k j}(i)$ - number of shortest paths from node $k$ to node $j$ that pass through $i$,

$g_{k j}$ - number of shortest paths from node $k$ to node $j$.

\section{Results and discussion}

We have analysed the communication network between project participants for residential building construction located in Rivne, Ukraine. Construction began in February 2019, and its completion is scheduled for September 2021. The study was conducted from June to July 2019 , at the stage design completion and 
beginning of construction work. Since communication is considered the central mechanism of iterative interaction (Mahmud, 2009), the initial stage of the study was identification of relationships between participants in construction project delivery. Each of its participants needed to determine persons with whom he communicated. Communication in the project takes place by phone, email or verbal form.

At the second stage of the study, communication strength between the network participants was calculated, that is, each graph edges were assigned a weight. Communication strength was calculated based on the method presented in Pryke et al. (2018) as a function of two variables: frequency and quality of communication. The frequency and quality of communications were calculated based on data collected from 17 project participants. An analysis of communication frequency was carried out using a five-point rating (less than once a week, once a week, several times a week, once a day, more than once a day, with an estimate of 1 to 5 points, respectively). To analyse communication quality, we used a three-point rating scale (low, medium, high) and three indicators - importance, accuracy and timeliness.

Then value of communication strength between nodes $i$ and $j$ can be determined by the formula

$E_{i j}=F_{i j} \cdot Q_{i j}$

where:

$F_{i j}$-communication frequency, which is calculated as $f_{i j} / 5$,

$Q_{i j}$ - communication quality, which is calculated as $q_{i j} / 9$.
The node weight is calculated as the sum of the weights of all the edges (communication strength) related with this node. An adjacency matrix of size $17 \times 17$ was formed based on value of communication strength between all the participants (edge weight).

The data from the matrix were used to calculate centrality measures (the table) and visualize communication network (Figs. 1-3).

Centrality measures calculation and visualization were implemented using NetworkX library in Python programming language. The positioning of graph nodes was implemented using Fruchterman-Reingold force algorithm (SpringLayout). In Figures 1-3, the abbreviation was used to Installation Design Office, IDO.

The analysis degree centrality of nodes (Fig. 1) observed a high value measure in network participants: "Project manager", "Architect" and "Construction site manager", which directly correlates with number of connections with other network participants.

The calculation of PageRank algorithm showed the same results of nodes importance in network as calculation degree centrality.

The analysis eigenvector centrality showed the highest values of measure were among participants "Project manager", "Design office" and "Construction site manager" (Fig. 2). At the same time, nodes "Project manager" and "Construction site manager" received a high value due to that they have many neighbouring nodes with a low level of impact in network. Node "Design office" got a high value due to that it had few 
TABLE. The centrality measures of the participants in construction project network

\begin{tabular}{|l|c|c|c|c|c|}
\hline Specification & $\begin{array}{c}\text { Number } \\
\text { of links }\end{array}$ & $\begin{array}{c}\text { Degree } \\
\text { centrality }\end{array}$ & $\begin{array}{c}\text { Betweeness } \\
\text { centrality }\end{array}$ & $\begin{array}{c}\text { Eigenvector } \\
\text { centrality }\end{array}$ & PageRank \\
\hline General construction supervision & 7 & 89.26 & 0 & 0.264 & 0.061 \\
\hline Project manager & 16 & 180.47 & 0.392 & 0.42 & 0.119 \\
\hline Construction site manager & 11 & 124.65 & 0.025 & 0.303 & 0.085 \\
\hline Construction works manager & 9 & 99.39 & 0 & 0.257 & 0.069 \\
\hline Construction engineer & 5 & 54.98 & 0 & 0.17 & 0.041 \\
\hline Architect & 12 & 131.05 & 0.142 & 0.301 & 0.091 \\
\hline Chief engineer & 7 & 87.73 & 0.008 & 0.271 & 0.06 \\
\hline Design office & 9 & 106.15 & 0.083 & 0.308 & 0.071 \\
\hline Chief mechanical engineer & 6 & 68.82 & 0 & 0.193 & 0.05 \\
\hline Surveyor department & 3 & 36.54 & 0 & 0.122 & 0.03 \\
\hline Safety engineer & 5 & 44.20 & 0 & 0.134 & 0.035 \\
\hline Delivery manager & 5 & 67.95 & 0 & 0.204 & 0.049 \\
\hline Estimate department & 3 & 28.61 & 0.025 & 0.091 & 0.026 \\
\hline Construction engineer & 5 & 64.24 & 0.025 & 0.177 & 0.048 \\
\hline Electrical installation design office & 6 & 82.21 & 0.008 & 0.236 & 0.057 \\
\hline Plumbing installation design office & 5 & 70.91 & 0 & 0.211 & 0.05 \\
\hline Gas installation design office & 6 & 84.52 & 0 & 0.238 & 0.059 \\
\hline
\end{tabular}

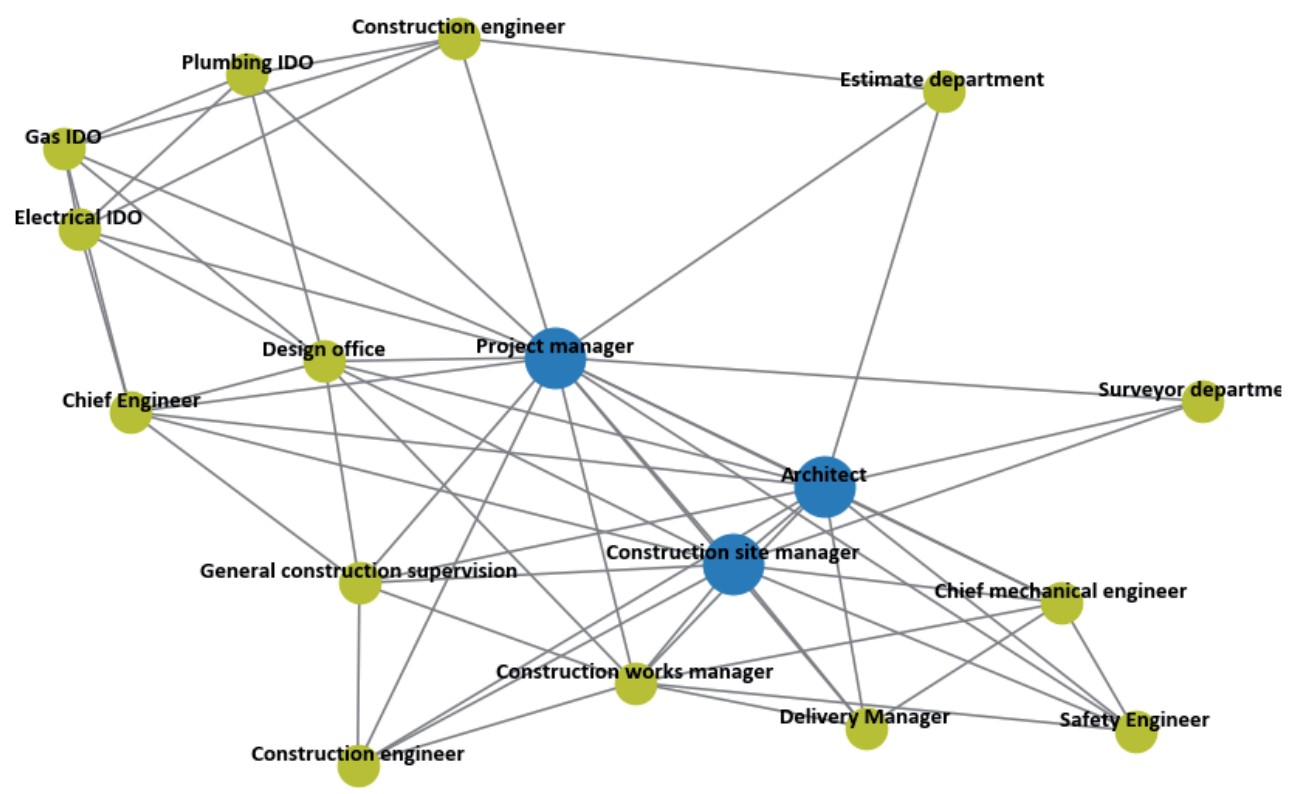

FIGURE 1. Degree centrality of nodes 


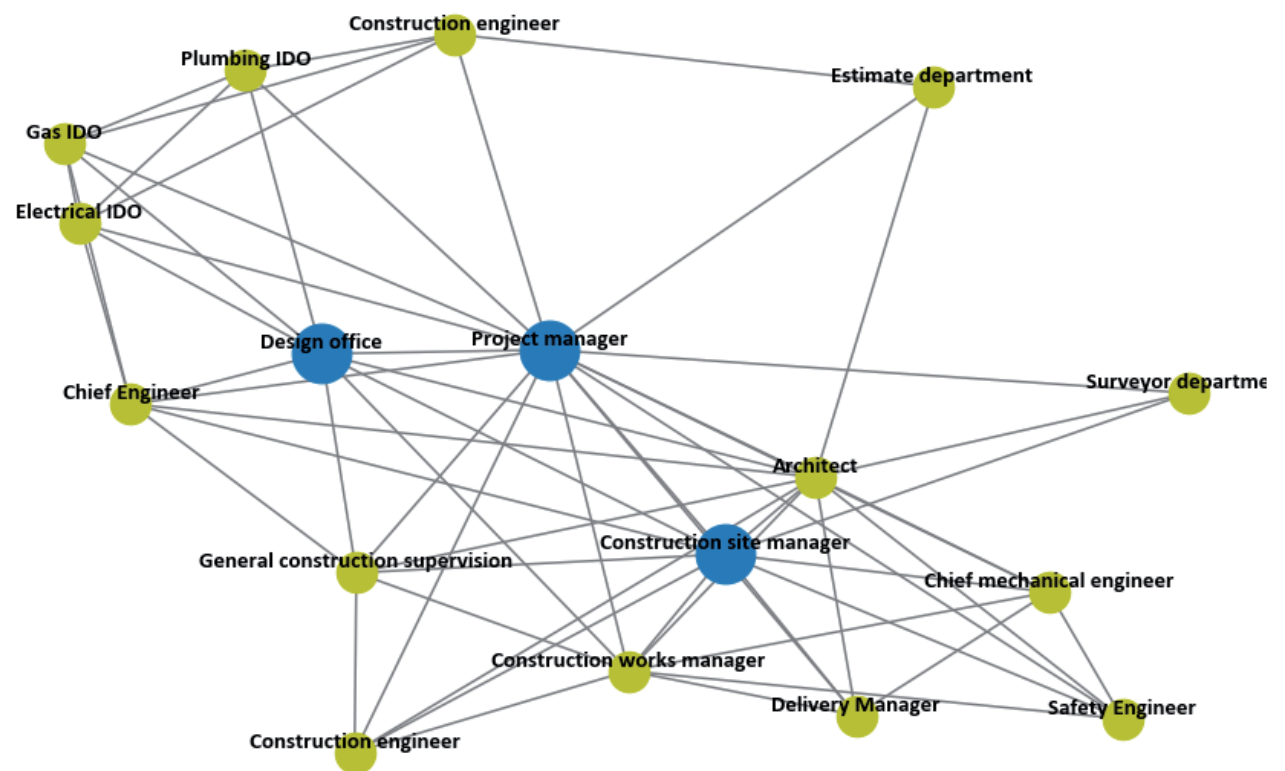

FIGURE 2. Eigenvector centrality and measure PageRank of nodes

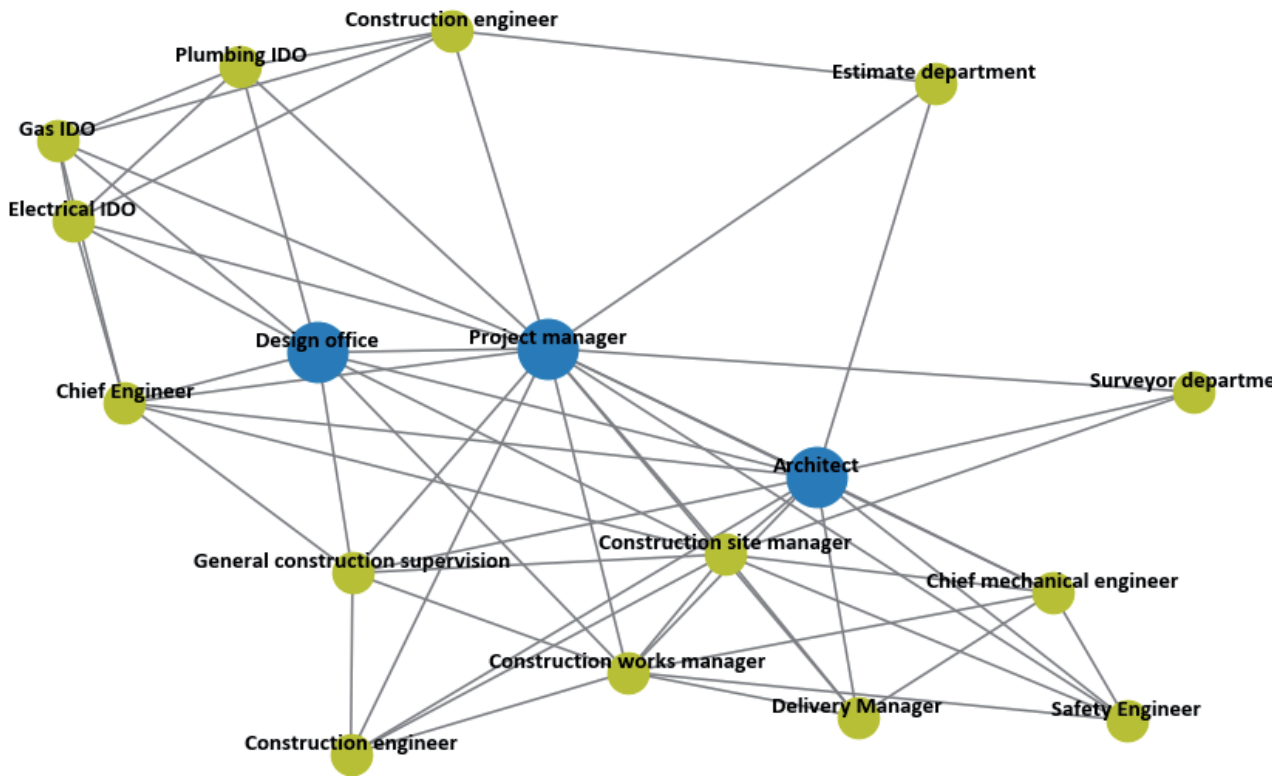

FIGURE 3. Betweeness centrality of nodes 
neighbours, but with a high level of influence in network.

The analysis betweeness centrality indicated the highest values of the measure were among the participants "Project manager", "Architect" and "Design office", which indicates them as the main brokers for knowledge and information sharing in this network (Fig. 3).

\section{Conclusions}

Project managers often want to understand how the interaction in the project occurs, how strong are the connections between team members, who is the key person, which information is transmitted efficiently and which is not. Use of SNA and calculation of centrality measures of network participants can help in solving these problems. Having analysed the centrality measures that were calculated for construction project network, we can conclude:

- high ratings of participants "Project manager", "Design office", "Architect" and "Construction site manager" can be assessed as normal for this project stage, since during the study of network there was a transition from design stage to start of construction works;

- the highest rating among all network participants for the calculated centrality measures had "Project manager". This is a positive fact since its main task is to coordinate and integrate project participants;

- the high impact of participant "Design office" in terms of eigenvector centrality and betweeness centrality indicates his importance for network communication, as he acts as broker and itself has connections with important project participants.

Further research will focus on continuing to analyse the project's communications network in the next stages of its delivery.

\section{References}

Abbsaian-Hosseini, A., Liu, S.M. \& Hsiang, S.M. (2017). Social network analysis for construction crews. International Journal of Construction Management, 19(2), 1-15.

Baiden, B.K., Price, A.D.F. \& Dainty, A.R.J. (2006). The extent of team integration within construction projects. International Journal of Project Management, 24(1), 13-23.

Bonacich, O.F. (1987). Power and centrality: a family of measures. American Journal of Sociology, 92(5), 1170-1182.

Bornholdt, S. \& Schuster, H. (eds.). (2003). Handbook of graphs and networks: From the genome to the Internet. Weinheim: WileyVCH Verlag.

Briscoe, G. \& Dainty, A.R.J. (2005). Construction supply chain integration: an elusive goal? Supply Chain Management: An International Journal, 10(4), 319-326.

Chinowsky, P. \& Songer, A. (2011). Organizational management in construction. New York: Spon Press.

Freeman, L.C. (1977). A set of measures of centrality based on betweenness. Sociometry, 40, 35-41.

Freeman, L.C. (1978). Centrality in social networks conceptual clarification. Social Networks, 1(3), 215-239.

Loosemore, M. (1998). Social network analysis: using a quantitative tool within an interpretative context to explore the management of construction crises. Engineering, Construction and Architectural Management, 5(4), 315-326.

Madani, F., Daim, T. \& Weng, C. (2017). Smart building technology network analysis: applying core-periphery structure analysis. International Journal of Management Science and Engineering Management, 12(1), 1-11. 
Mahmud, S. (2009). Framework for the role of self-organization in the handling of adaptive challenges. Emergence: Complexity and Organization, 11(2), 1-14.

Marsden, P. \& Lin, Y.N. (1982). Social structure and network analysis. Beverly Hills: Sage Publishing.

Nicolini, D., Holti, R. \& Smalley, M. (2001). Integrating project activities: the theory and practice of managing the supply chain through clusters. Construction Management and Economics, 19(1), 37-47.

Ochieng, E.G. \& Price, A.D.F. (2009). Framework for managing multicultural project teams. Engineering, Construction and Architectural Management, 16(6), 527-543.

Page, L., Brin, S., Motwani, R. \& Winograd, T. (1999). The PageRank citation ranking: Bringing order to the web. Technical report 1999-66. Stanford: Stanford InfoLab, Stanford University.

Project Management Institute [PMI] (2000). A Guide to the Project Management Body of Knowledge (PMBOK Guide). Edition 2000. Newtown Square, PA: Project Management Institute.

Pryke, S. (2005). Towards a social network theory of project governance. Construction Management Economics, 23(9), 927-939.

Pryke, S. (2012). Social network analysis in construction. Oxford: Wiley and Sons.

Pryke, S., Badi, S., Almadhoob, H., Soundararaj, B. \& Addyman, S. (2018). Self-organizing networks in complex infrastructure projects. Project Management Journal, 49(2), 18-41.

Radziszewska-Zielina, E., Śladowski, G., Kania, E., Sroka, B. \& Szewczyk, B. (2019). Managing information flow in self-organising networks of communication between construction project participants. Archives of Civil Engineering, 65(2), 133-148.

Śladowski, G., Radziszewska-Zielina, E. \& Kania, E. (2019). Analysis of self-organising networks of communication between the participants of a housing complex construction project. Archives of Civil Engineering, 65(1), 181-195.

Trach, R. \& Lendo-Siwicka, M. (2018). Zastosowanie sieciowej struktury organizacyjnej $\mathrm{w}$ zintegrowanej realizacji przedsięwzięcia budowlanego [Network organizational structure ap-plication in integrated project delivery]. Scientific Review - Engineering and Environmental Sciences, 27(1), 82-90.
Trach, R., Pawluk, K. \& Lendo-Siwicka, M. (2020). The assessment of the effect of BIM and IPD on construction projects in Ukraine. International Journal of Construction Management, 1-8.

\section{Summary}

Analysis of communication network of the construction project participants. The construction industry is characterized by limited resources and a high level of competition. Limited resources and a competitive environment determine knowledge and information as a particularly important resource for the development of the construction industry. A communication network is one of the elements of a knowledge management system in projects and serves to organize and maintain information links between project participants. We have analysed the communication network between project participants for residential building construction using social network analysis (SNA). The purpose of this work is the calculation and analysis centrality measures for participants in the construction project delivery. Centrality measures can answer the following questions whether the node is influential or central to the network and whether the node is critical for the flow of information in the network.

\section{Authors' address:}

Roman Trach

(https://orcid.org/0000-0001-6654-9870)

Szkoła Główna Gospodarstwa Wiejskiego w Warszawie

Instytut Inżynierii Lądowej

ul. Nowoursynowska 159, 02-776 Warszawa

Poland

e-mail: roman_trach@sggw.edu.pl

Sergey Bushuyev

(https://orcid.org/0000-0002-7815-8129) 